\title{
The Ethics of TESOL a quarter century on
}

\author{
ALAN WILLIAMS \\ Honorary Fellow, Melbourne Graduate \\ School of Education, University of Melbourne.
}

Abstract: Discussion of ethical considerations in Australian TESOL began 25 years ago, with arguments about the need for TESOL professionals to be aware of the potentially harmful consequences of their work, the loss of first language proficiency, and even the loss of languages themselves (Williams, 1992, 1995). The intervening quarter of a century has seen sweeping changes to the context in which TESOL professionals work and developments in our professional knowledge about the processes and consequences of TESOL professional practice (Canagarajah, 1999; Phillipson, 1992, 2013). In this paper developments in the sociocultural context of TESOL, the general education context and the TESOL professional context are explored. This article revises the arguments about ethical directions in TESOL presented a quarter century ago to take account of these changes. Guiding principles for individuals and professional bodies are identified. It is argued that our role is to sensitively help our learners to explore the potential consequences of the learning of English, and for professional bodies to take an active role in advocacy given the impact of globalization processes, more centralized curriculum and assessment frameworks, and the relatively reduced capacity of individual teachers to influence the institutions that employ them.

Keywords: Ethics in TESOL, Professional practice in TESOL, Australian TESOL, impact of TESOL on learners, changes in Australian TESOL.

\section{Introduction}

It is a quarter of a century since The Ethics of TESOL was published in TESOL in Context (Williams, 1992). That article was written after I had attended an international conference and heard reports that it was not possible to replicate some research on Navaho language because most speakers of the language had ceased using their traditional language and were using English instead. I was taken aback that what I considered the "good" work 
of teachers of English in this situation could have contributed to this sad situation. At that time, I also read Robert Phillipson's Linguistic Imperialism (Phillipson, 1992) that described how the global spread of English in the late 20th century served the interests of corporations, governments and individuals, including teachers of English, in the English-speaking world, but had not necessarily benefited learners of English. In fact, Phillipson argued that it had brought disadvantages to many, by diminishing the status of the (not English) languages they spoke, or by defining their skills and worth through the extent to which they are proficient in English. I was prompted to question whether the work we performed in TESOL, which I considered, and believed our profession considered, as "good" work that brought benefits to our learners, could have a sinister side and produce harmful consequences. Three years later, I wrote a second article using the provocative title TESOL and cultural incorporation: Are we doing the devil's work? (Williams, 1995) in which I argued that we need to explore the results of our actions and that it is not enough to assume that because our intentions are "good" our work cannot have harmful consequences.

This special issue of TESOL in Context presents an opportunity to revisit these discussions in light of developments in the intervening period, and to explore the extent to which the arguments presented at that time still have relevance to TESOL in Australia .

The arguments presented in the early 1990 s were that TESOL professionals had to be aware of and take responsibility for the consequences of the work we do. We need to be mindful that in teaching English as an additional language (EAL) we should not be part of processes that deprive our students of their linguistic and cultural heritages, and that our work does not lead to the diminution of, or threaten the existence of the languages and cultures our students bring to their development towards becoming bi/multilinguals with English as part of their linguistic repertoires. A foundation of the arguments presented then was that we cannot assume that the consequences of what we do are automatically "good" just because we start with "good" intentions.

The last quarter century has seen significant changes in both the way our work is organized and our professional knowledge. As well as increased globalization, there have been significant changes in the organization of educational provision in Australia, especially in the adult sector, including the adoption of business- 
oriented models of educational provision. These changes mean that we now work in a more competitive and less cooperative professional environment. Standardized assessments of students have also become much more central to our work, with the results of such assessments having a big role in the learning pathways of our students, as well as how our work is evaluated. Our professional knowledge has been augmented by a body of research stimulated by Phillipson's (1992) work, which has come to be referred to as "critical applied linguistics", as well as understandings of greater diversity in what is considered the nature of English as it is used around the world. This work has not only challenged the profession to think about the consequences of our work, but challenged us to understand our work in the context of unequal power structures and local conditions to work in ways that challenge the reproduction of existing oppressive and marginalising social forces that limit our learners' opportunities more than our traditional focus "language proficicency" or "academic skills" (Norton \& Toohey, 2004).

\section{Changes in the sociopolitical context of TESOL in Australia}

There has been unprecedented integration of people and economies around the world. This has changed the roles and practices of governments. These processes have been aided by, and in turn, stimulated the remarkable development and application of information and computer technology (ICT), to the point where the "technology revolution" is seen as parallel to the industrial revolution of the 18th and 19th centuries. Within Australia, the end of bipartisan political agreement about immigration levels, and harsh political responses to refugee flows have created fear of, and hostility towards certain types of refugee movements and arrivals. These circumstances create a very different context from that shaping the TESOL profession in Australia when we started to discuss ethics in the early 1990s.

\section{Globalization processes}

Global integration over the last 25 years has continued and accelerated a process that commenced well before the early 1990s. Movement of people, products and ideas has greatly increased, can occur in multiple ways, and can be quite rapid. Reductions in transport costs together with easy and instant communication mean that locality and distance are much less significant in relation to the movement of people, products or the spread of ideas than was once the case. While some areas still remain 
remote and less accessible, the extent of such areas is diminishing. The English language, along with ICT elements such as the worldwide web, are lubricants for this process, meaning that English is the predominant (though not the only) global lingua franca. The TESOL profession has contributed to these developments through increasing professionalism and systemization of teaching English to speakers of other languages. One consequence of this is that the number of people who speak English as a second or additional language far exceeds the numbers of native speakers of the language (Kirkpatrick, 2007).

People move more (Castles et al., 2014). As well as international students, immigrants are more mobile, and more likely to retain stronger affiliations with their country of origin. It is easier for immigrants to travel, revisit and remain in contact with their country of origin, making migration a less pervasive experience than it once was (Williams \& Setijadi-Dunn, 2011). For many, migration has become a more temporary experience, for as circumstances change it has become easier and more attractive to return to one's country of origin. There is increased blurring between periods of expatriate residence in another country and staying on to eventually become a citizen of a new country. People have greater consciousness of areas beyond the locality in which they live. The notion of mobility has become more prominent, taking on a global, rather than social, connotation (Scheller 2011).

These changes mean our work can be seen as related more to people at a particular point of movement in ther lives, and less at the beginning of a once-only transition in their life to either live or study in an English-speaking country.

The influence of "neoliberal" ideas about the value of market forces and the importance of "small government".

Concurrent with these globalization processes has been widespread adoption of classical liberal economic theory in various forms by governments of different political perspectives. These ideas hold that market forces should control economic and public service activity, and that government should have minimal interference in these forces. Minimal government activity is seen as "good", so taxation and revenue raising measures are not a disincentive to "productive activities". The major political parties in Australia have taken up such ideas, and while there are differences of degree, both the Liberal / National Coalition and the Australian 
Labor Party have moved in this direction. This process commenced in the 1980s and has been continuing since, so it is now almost impossible to see any area of government activity that has not been significantly transformed.

These ideas have come to exert influence over the way education is organized and practised. This is particularly the case in the adult TESOL sector, where competitive tendering for program funding has become the norm. School education has not been immune to the effect of these ideas either, with increasing portrayals of schools as being in competition with each other. While there has been a significant private sector in TESOL in Australia since the 1980s, there has been a shift away from a predominantly public-sector and collaborative model of provision, to one where private sector patterns of organization apply, even within publicly-funded TESOL programs such as the Adult Migrant Education Program (AMEP) (Atkinson, 2014).

The changes mean we work less as autonomous professionals within institutions with a public service mission, and more as employees of organisations working in a competitive and commercial-like environment.

\section{Digital technology, the internet and English}

ICT was in its infancy in the early 1990s. Personal computers, the internet, email and the world-wide-web were novel technologies that we were just beginning to use and explore. There were no smart phones, tablets, apps or even wifi at that time. English has been a significant language in the mediation of the development of ICT. While other languages, especially Mandarin, are becoming more frequently used and significant in ICT communication, the use of English in internet communication mirrors its wider use as the predominant global lingua franca. This is transforming the language itself, and language particular to digital communication, such as the abbreviations used in SMS and emails, have become part of the language that our students encounter and that we need to teach. This is part of the normal adaptation of the language to its use in new domains. Many online users of English bring their features of English as it is spoken and written in different parts of the world, so the norms of native-English speakers from countries like Australia, the UK, Canada and the USA are less relevant and pervasive than they once were as models and goals for learners and users of English to aspire to, or to regulate their use of the language. The language we teach is taking new forms, which 
originate from a wider range of sources than used to be the case. The interconnection provided by the internet has sped up these processes to such an extent that English is constantly changing, and never seems "fixed".

Increased politicisation of immigration, refugee intakes and asylum seekers: the end of bipartisanship

In the post-war period there was broad political consensus that immigration levels and acceptance of refugees, including asylum seekers, were in Australia's best interests. This remained in place in the 1990s, but since about 2000 has become more contested, although to some extent both the Liberal/National Coalition and the Labor Party have shifted from fostering positive attitudes to refugees to trying to outdo each other in showing how "tough" they can be, even at the cost of inflicting great misery and contravening international treaty obligations. There has also been greater questioning of the benefit of immigration levels as a whole.

These shifts in the political context have meant that TESOL has changed from a context in which we could feel our work was widely valued and supported by political parties and the population at large. While our work is still widely seen as important, there are also some loud voices questioning the immigration and globalisation processes our work is related to. Some of these voices are on political margins, but some of the arguments they make are being taken up by mainstream politicians and being pursued more actively in the form of arguments for restrictions to immigration intake and questioning the value of refugee and humanitarian elements of the immigration program. The context, if not the nature, of our work is becoming more contested and less taken for granted in public discourse. There is less certainty about about the circumstances of our work.

\section{Changes in the general educational context}

The organisation and practice of education has changed significantly in the last quarter century. While changes were taking place in the 1990s, educational institutions and educationalists were still largely seen as the experts in the field who should determine the direction of education. There is now less deference to education experts, and politicians, spokespersons for various lobby groups and many others, including members of the general public, frequently voice dissatisfaction and criticism 
of the education system and its practices or outcomes.

As a result, education has become more contested, with farreaching measures being advocated, implemented, and changed with the ebb and flow of changes in government, or even ministers within the same government. Three trends have been evident :

1. A shift from predominantly collaborative to competitive modes of operation

Education was a quite collaborative enterprise in the early 1990s. There were exceptions in private sector institutions, but even these involved some sense of a larger common activity and purpose. In both school and adult sectors, institutions and teachers often worked together to provide clear pathways and find appropriate courses for students. More competitive models now mean schools and institutions ("providers") are seen, and present themselves, as competing for student enrolments by "selling" their perceived advantages compared to others in order to maximise their enrolments, and increase their income. This has been the case in both school and adult contexts.

\section{Increasing standardisation of curriculum and assessment}

In both school and adult sectors, there has been extensive national effort to develop unified curriculum frameworks, so schools and education providers are expected to teach within the same framework. This approach allows comparisons of outcomes and results between schools and providers, adding to the competitive environment in education. In school education systems, standardised assessment regimes, such as NAPLAN (National Assessment Program - Literacy and Numeracy) are used to compare the performance of children in different schools, school systems, and states, nationally. Internationally, procedures such as PISA (Program for International Student Assessment), TIMSS (the Trends in International Mathematics and Science Study) and PIRLS (the Progress in International Reading Literacy Study) are used for the same purpose. Results of these assessments, as well as year 12 results are compared to see who is outperforming "competitors" and who is "falling behind", even when this comparison is not the intended primary purpose of the assessments. In the adult sector, accredited certificates, such as CSWE (Certificates in Spoken and Written English) provide a goal for teaching and rates of achievement on these are often an element of evaluation of teaching quality in an institution, and are used as 
measures of the effectiveness of providers. There is more widespread use of international tests of English such as the IELTS in the tertiary sector, as well as increasingly, for more general purposes such as eligibility for migration or permanent residency in Australia. The result of such developments is an increasing focus on teaching for desirable results as defined by the assessment instrument, with teachers within sectors increasingly teaching similar content, often in similar ways, rather than tailoring content and styles of teaching to meet the particular needs of specific groups of students in individual classes, schools or learning centres.

As a result our teaching is increasingly expected to contribute to positive results on very specific assessment measures of importance to the schools and institutions we work for.

\section{Provision for international student}

International education was an emerging and rapidly developing activity in the early 1990s. At that time it was largely restricted to TESOL courses (often referred to then as ELICOS - English Language Intensive Courses for Overseas Students). It has now developed to become an extremely important part of the education provision in Australia, embracing much more than English language courses. It is a major export earner in the Australian economy, along with industries like minerals and tourism, and Australia has become a world leader in this field. Every educational sector has significant international provision, and some colleges and schools have a sole or major focus on serving international students, either on shore or off shore. For some schools and many adult sector providers income from international students and programs has become an important source of funding, and efforts are made to be attractive to this part of "the market". The work of TESOL teachers, especially in schools, is increasingly directed toward contributing to institutional goals of attracting international students.

\section{Changes in the TESOL professional context}

Partly as a result of these changes, important aspects of our professional knowledge and perspectives have also undergone significant change. These changes relate partly to our professional knowledge and understanding, and the organization of TESOL work. 


\section{TESOL professional knowledge and understanding}

The collective professional knowledge and discourse of the TESOL profession as reflected in international and local journals, conferences and publications have changed in two significant ways in the last 25 years:

1. Greater understanding of diverse varieties and models of English, rather than a focus on "native-speaker norms"

Our understanding of the language we teach, English, has developed in significant ways, along with the evolution of communicative language teaching (CLT) widely accepted by our profession since the $1970 \mathrm{~s}$. It is easiest to understand this by considering the way our profession (along with our colleagues involved in the teaching of other languages) has been guided by what we call communicative approaches to language teaching. In its earliest phases, communicative language teaching emphasised the "native-speaker model" as the target of learning. Needsfocused teaching meant that a key goal of student learning was the way native speakers of the language use it in the situations relevant to the lives of learners, such as in the workplace, in academic study or social interaction. The language of native-speakers was the target of learning. So learning "Australian English" made sense in a context where immigrants and learners saw themselves as living the rest of their lives in Australia, or for international students staying long term to obtain a qualification. However, the logic of CLT in the era of globalisation has led to the realization that English is more often used in interactions between non-native speakers than between native-speakers. So the logic and value of the native speaker version of the language has been called into question. Instead, there is increased interest in "international English" and what happens when English is used as an international lingua franca, including the nature of different non-native or second language varieties of English (such as Singaporean English, Indian English, Thai English and so on) are now generally recognized as legitimate varieties of the language (see, for example Kirkpatrick, 2007). The goals of our teaching are now framed with greater understanding of such issues, rather than asserting a standard based on a native-speaker variety of the language as the privileged model. The models of language we teach have come to be more broadly identified than in the earlier phases of communicative language teaching, which emphasized 
"native-speaker" norms as the goal of teaching. Increasing diversity of our profession means many successful learners of English, bring a wider range of competent models of English to our learners, contributing to this process.

\section{Insights from "critical applied linguistics"}

A second development in our professional knowledge is the development of critical applied linguistics that flowed from Phillipson's work in the early 1990s. Phillipson's work, which is on-going (for example, Phillipson, 2013), raised the issue of deleterious and harmful consequences of many dimensions of the professional practice of TESOL. It drew a range of strong responses and reactions. Some supported the thrust of Phillipson's argument, and went on to further analyses that extended and confirmed his argument, such as Pennycook's analysis of the role of English language teaching in colonial India and South East Asia which was related to current TESOL ideologies (Pennycook, 1998). Other responses questioned or rejected Phillipson's argument, including significant critiques from what he called the periphery; the non-native speakers he saw as being exploited and marginalised by TESOL practices. Bisong (1995) argued that Phillipson's work was in fact yet another example of native English speakers putting non-native speaking learners and teachers in a marginal position, denying their own agency and ascribing all power and capacity to native-speaking teachers from "the centre". This was taken further by Canagarajah's work that showed that learners of English indeed exercised agency in their learning of English, and learnt and used it for their own purposes. They managed English learning and used the language in their lives in ways that were quite different from the expectations and purposes of their teachers (Canagarajah, 1999).

These contributions to our professional knowledge have not only alerted us to potential harmful consequences of our work, but have also shown us it is our learners who decide how they will use English and the place it holds in their lives. It is the actions of our learners in using English in their lives that will ultimately determine the consequences of our teaching. As teachers we do not, and should not, control the actions and choices of our learners. As well as equipping them with language skills, we support them by helping them to understand and learn to negotiate the sociolinguistic, social, political and economic 
structures, perceptions and pressures they encounter in using English to achieve their personal and collective goals.

\section{The organization of our professional employment and work}

Oliver et al. (2017) provide a recent and comprehensive overview of the evolution of the TESOL profession in Australia, including showing how the status of EAL programs in schools has been becoming (even) more precarious. They argue that EAL in schools is increasingly pressured to be integrated into mainstream concerns and assessment imperatives. The analysis of the precarious positions of teachers in adult ESL sector in a competitive tendering regime presented by Bertone (2000) still holds. Adult ESL teachers are no longer considered stakeholders in the organisations in which they work, but as temporary servants who provide a specific service. They are expected to work within specific statements of their duties, and directions of the organisation are set by management, who are responsible for meeting the demands and preferences of funding bodies. The situation in schools has come to resemble what developed earlier in the adult sector, where there is less room for independent ethical decision making by teachers, with strong expectations of them meeting broad institutional goals, rather than being advocates for their discipline and students as was more common, although certainly not universal, in the early 1990s.

As we come to feel less secure in our employment with less capacity to shape the goals and practices of the organisations and institutions we work for, not to mention the funding bodies and policy makers that set up the parameters shaping what our employers do, we can feel that we have less control control over the consequences of our work for our learners. This is in contrast to the early 1990s when we worked with higher levels of permanency and more consultative organisational structures conducive to the development of stronger agency and selfconfidence among teachers about our capacity to shape most facets of our work.

\section{Ethics and TESOL in the "20teens"}

The more complex and varied environment in which we teach and the dynamics of English as a global language have broadened the domain of our professional work, and require us to think beyond our local context when considering the nature and implications of our work. Yet the pressures of our workplaces, the increasing 
focus of teaching towards outcomes on standardised curriculum and assessment frameworks press us to have a narrower focus and more specific goals in our work. Increasingly precarious employment conditions and status mean that individual TESOL professionals have less capacity and confidence in enacting ethical positions they identify. However, the insights of critical applied linguistics, that our learners will ultimately determine the outcomes of our work, and that our learners will make their own decisions and actions change our role from a profession-centric view that we will determine the outcomes of our work, to an understanding that we play only a partial role in the processes that lead to the consequences of our teaching. We act in concert with both the institutions we work within and our learners (and in the case of children, their families) to contribute to the outcomes of the learning we stimulate in working with our students.

These understandings lead me to see a need to revise the view I presented 25 years ago. From this distance, some aspects of my arguments seem paternalistic, and over confident about our capacity to control the outcomes of our work. Nevertheless, our professional knowledge and outlook, along with the criticisms of writers such as Phillipson, lead me to argue that we still need to consider the ethical dimensions and implications of our work. But we need to do this from an understanding of what motivates our ethical beliefs, as well as understanding that we need to use them not so much to guide us to an outcome, but to lead us into a more dialogical relationship with our learners (and their families) that will help them develop understandings of the consequences and implications of choices they make related to their learning of English. We also need to consider how we are postioned, and position ourselves, within our employing institutions in order to project an ethically informed view of our work to our employers.

There are two levels from which we can think about the articulation and application of ethics in our profession. The first is the individual level, the ethical stance and actions of each of us as individuals, and secondly, the collective ethical position of our profession, as expressed through our professional associations.

Ethics relate to the moral principles that guide us in our behaviours, and are founded on values, which in turn are derived from our belief systems. Ethics for TESOL can be considered to lie within two broad approaches of ethical theory; applied ethics, the ethics of particular fields of activity, and consequential ethics, a concern with the results and consequences of actions as well as 
the ethical dimensions of the actions themselves. Ethics involves a concern with actions and outcomes that are "good" and do not cause harm. We need to understand these foundations to determine our positions on particular issues.

\section{Personal ethics and frameworks}

At the individual level we each explicitly or implicitly create and work within our own idiosyncratic ethical framework. This involves the values and experiences we bring to our work, and how these guide us in what we do. This is likely to intersect with our view of the world, derived from any religious, or philosophical outlooks we adhere to, or to reflect an apparently pragmatic (and perhaps inexplicit) worldview and theories of action. This incorporates our view of how things are, and how they should be. It also involves a view of ourselves in the world and the extent to which we see ourselves as having agency in the face of the social structures around us, the institutional, class, gender, race and socioeconomic environment in which we live and work. Here, we are all individuals, and as well as having different value systems, differing ideas about our agency can mean different individuals place different emphases on ethical considerations, as well as having different attitudes to similar situations.

Within our profession, the individual differences in ethical perspectives may mean different teachers are willing to work in different types of programs or institutions, or will wish to intervene in certain situations while their colleagues may wish to intervene in different ways, or not intervene at all, or have different ideas about what should (or shouldn't) be done in specific situations.

To apply my argument of the 1990s here, what is important is that as individuals we are aware of our personal ethical stance, reflect on it and keep ourselves satisfied that we are comfortable doing what we do. Further, it requires that where we make some compromise, we understand what we are doing and why we are doing it. This does not prescribe any course of action, other than the requirement to reflect on the impact and implications of our own work, and be comfortable with that. It's a good idea as a personal concern, so we don't suddenly find we have done something we wish we hadn't - but even here different individuals may have different ideas about this, with some agreeing that this is important, while other may say they don't see this as an issue for themselves. 
A change from my argument of the 1990s is to recognise that our students (and in the case of children, their parents or guardians) are active in making decisions for themselves. Our role must be limited to using our professional knowledge and skills to assist them in advisory ways, in understanding the dimensions of issues and choices they may make, so they are better informed and better able to exercise agency based on their own values and understandings. We can improve our learners' awareness and reflexivity in their decision making by providing input they may not otherwise have. But their decisions must be their own. Any input we provide must be given appropriately sensitively and respectfully, and there will be instances in which it will not be appropriate for us to be involved in decision making at all, such as when a learner's religious beliefs or affiliations lead them to a particular course of action. There may be circumstances where our views may be in conflict with those of our learners. Our role in such circumstances is to use our professional knowledge to point out consequences and implications we may be aware of, but of which our learners and their families may not. For example when a family informs a teacher they will only speak English at home and not use their native language. Other cases may involve helping learners find ways of meeting competing needs, such as spending time in English classes, or leaving in order to earn money to provide immediate financial relief to the family. In other cases our personal values (which may accord with general societal values), don't coincide with those of particular learners or their families, such as when a husband says, "My wife has to leave English classes to look after the home". We need to negotiate our way through such circumstances, knowing what motivates our views, but also finding ways to respectfully help learners become aware of the implications we see. Ultimately, if we are to respect our professional values of tolerance and respect, we have to accept the rights of learners to make their own informed decisions, even if we have tried to help them consider other possibilities. In the end, learners may make decisions we do not agree with, but our role is not to prevent this, but to ensure the decision is made after information about real or potential consequences has been respectfully provided.

\section{Professional ethics and principles}

Given the changed nature of the professional and institutional structures of education, it is more difficult to understand as well 
as articulate a collaborative and professional ethical stance. This only exists to the extent to which we work in structures that bring us together, although our shared training and induction into professional work will give us shared perspectives and concerns. Our collective ethical stance will be realised in the policies and advocacy work of our professional bodies. Language educators usually share an appreciation and valuing of the existence of different languages, so the underling value that informs TESOL professional ethics is a respect for and valuing of multiple languages and associated cultures in the lives of individuals and communities and language diversity. Advocacy of TESOL organisations needs to be related to the rights of our learners and the ways they are treated in TESOL programs, and at times, related aspects of their lives, and needs to address policy proposals and settings as well as the way policy is implemented by systems and insitutions and the dynamics that come into play in classrooms. These positions need to be related to the rights of our learners and their communities, the ways they are treated in TESOL programs, and related apsects of their lives.

The circumstances in which we now work mean our professional bodies need to work harder than before to project the voices of individual teachers on professional ethical issues, given our generally weaker status within the institutions in which we work. Our voice and perspective are important. In addition, the greater influence of more widely used standardizing curriculum and assessment frameworks, and the increasing use of standardized assessment data to make comparisons about our students in a competitive environment create an imperative for TESOL professional bodies to be prominent and forthright in presenting and advocating an additional language learning-informed analysis of the nature and consequences of structures and processes related to our work, and the broader experiences of our students.

To do this, our professional bodies need to be aware of the sorts of issues raised by research into the ethics and consequences of TESOL, and to be informed about them. This requires gathering information and conducting research in order to be able to make strong and credible cases. It also involves collaboration with other organisations with similar and related values, perspectives and interests. This can include other language teachers, ethnic community groups and organisations who work on advocacy and support for our students and their communities, including refugee and international student support bodies. 
While TESOL organisations have always done this and still are doing it, our current circumstances make the projection of a strong and credible ethically-driven perspective on issues affecting our students more important than ever.

\section{Conclusions}

A quarter of a century has elapsed since we began to explicitly discuss the ethical dimension of our professional work. In that time there have been enormous changes to the context of our work, as well as greater insight within our professional knowledge about how we and our learners affect the nature and consequences of our work. These changes mean that while it is important and inevitable that as individuals we will consider the consequences and implications of our work, this needs to be done in consultation with our students, leaving them in a position to make their own informed choices about the place English will take in their lives. In this respect, our role is constrained to helping inform them of issues that may be relevant to them, and of which they may be unaware.

At the professional level, the changes described here mean that TESOL professional organisations need to be strong in articulating how current practices and structures can and do inflict harm on our learners and the groups they come from, and advocate practices and solutions to eliminate, or if that is not possible, alleviate the problems we identify. The relatively weaker position of individual teachers makes this a stronger imperative than it has ever been.

\section{Acknowledgement}

I would like to thank the two anonymous TESOL in Context reviewers whose insightful comments and suggestions have helped and guided me in making revisions and improvements to the draft article that was originally submitted.

\section{References}

Atkinson, M. (2014). Reframing literacy in adult ESL programs: Making the case for the inclusion of identity. Literacy and Numeracy Studies, 22(1), 3-20. doi:http:/ /dx.doi.org/10.5130/ lns.v22i1.4176

Bertone, S. (2000). ACTA Background Paper No. 5: Casualisation of the ESL workforce in Australia. TESOL in Context, 10(1), 28-36. 
Bisong, J. (1995). Language choice and cultural imperialism: a Nigerian perspective. ELT Journal, 49(2), 122-132. doi:10.1093/elt/49.2.122

Canagarajah, A. S. (1999). Resisting linguistic imperialism in English teaching. Oxford, UK: Oxford University Press.

Castles, S., de Haas, H., \& Miller, M. (2014). The age of migration: International population movements in the modern world, 5th edn. Basingstoke: Palgrave Macmillan.

Kirkpatrick, A. (2007). World Englishes: Implications for international communication and English language teaching. Cambridge: Cambridge University Press.

Norton, B \& K. Toohey (eds.) (2004). Critical pedagogies and language learning. Cambridge: Cambridge UP.

Oliver, R., Rochecouste, J., \& Nguyen, B. (2017). ESL in Australia - a chequered history. TESOL in Context, 26(1), 7-26. doi: https://doi.org/10.21153/tesol2017vol26nolart700700

Pennycook, A. (1998), English and the discourses of colonialism. London: Routledge.

Phillipson, R. (1992). Linguistic imperialism. Oxford: Oxford University Press.

Phillipson, R. (2013). TESOL expertise in the empire of English. TESOL in Context, 22(2), 5-16.

Scheller, M. (2011). Mobility. Sociopedia.isa. doi: 10.1177/ 205684601163

Williams, A. (1992). The ethics of TESOL. TESOL in Context, 2(2), 4-5.

Williams, A. (1995). TESOL and cultural incorporation: Are we doing the devil's work? TESOL in Context, 5(1), 21-24.

Williams, A. \& Setijadi-Dunn, C. (2011). Visiting 'home' contacts with the homeland, self reflexivity and emergent bilingual identities. TESOL in Context, 21(1), 42- 58.

Dr. Alan Williams has worked in TESOL teacher education and research for over 25 years, including at La Trobe University, Bundoora and the Melbourne Graduate School of Education. He has taught in Australia, Canada, the UK, Vietnam and recently in China. He was the ACTA Policy Convenor in the early 1990s.

Email: alanwilliamsconsulting@yahoo.com.au 